Tohoku J. Exp. Med., 2007, 211, 115-120

\title{
The Safe Limits of Mechanical Factors in the Apnea Testing for the Diagnosis of Brain Death
}

\author{
Çimen Olguner, ${ }^{1}$ UĞur Koca,,${ }^{1}$ Mert Akan, ${ }^{1}$ Ayşe Karci ${ }^{1}$ and Zahide Elar ${ }^{1}$ \\ ${ }^{1}$ Department of Anesthesiology and Reanimation, Dokuz Eylül University, School of Medicine, \\ Izmir, Turkey
}

Olguner, Ç., Koca, U., Akan, M., Karci, A. and Elar, Z. The Safe Limits of Mechanical Factors in the Apnea Testing for the Diagnosis of Brain Death. Tohoku J. Exp. Med., 2007, 211 (2), 115-120 — Apneic oxygenation is an apnea testing method in the diagnosis of brain death. In this method, oxygen $\left(\mathrm{O}_{2}\right)$ is delivered into the trachea via an $\mathrm{O}_{2}$ catheter $\left(\mathrm{O}_{2} \mathrm{C}\right)$. However, barotrauma may develop during $\mathrm{O}_{2}$ insufflation into the trachea. Oxygen catheter diameters, $\mathrm{O}_{2}$ catheter tip position in the trachea, and $\mathrm{O}_{2}$ flow rate have been proposed as causes of barotrauma. This study was designed to highlight the airway pressure changes during apneic oxygenation in a model consisting of an anesthesia bag, which was connected to a pressure transducer and to an endotracheal tube (ETT). The pressure of the system was monitored while delivering $\mathrm{O}_{2}$ continuously to the system through $\mathrm{O}_{2} \mathrm{C}$ of different diameters, which were placed in the ETT. Tested variables were ETT $/ \mathrm{O}_{2} \mathrm{C}$ ratio, $\mathrm{O}_{2} \mathrm{C}$ tip position in ETT (proximal $1 / 3$ of the ETT, mid point of the ETT, and distal $1 / 3$ of the ETT) and $\mathrm{O}_{2}$ flow rate $\left(6,8\right.$, and $\left.10 \mathrm{~L} \mathrm{~min}^{-1}\right)$. The increase in the airway pressure significantly correlated with $\mathrm{O}_{2} \mathrm{C}$ tip position in ETT $(p=0.017)$. ETT $/ \mathrm{O}_{2} \mathrm{C}$ ratio smaller than 1.75 caused significantly high airway pressures $(p<0.05)$. The pressure was significantly higher at the flow rate of $10 \mathrm{~L} \mathrm{~min}^{-1} \mathrm{O}_{2}$ compared with the flow rate of $6 \mathrm{~L} \mathrm{~min}{ }^{-1} \mathrm{O}_{2}(p<0.01)$. Thus, ETT $/ \mathrm{O}_{2} \mathrm{C}$ ratio, $\mathrm{O}_{2} \mathrm{C}$ tip position in ETT and $\mathrm{O}_{2}$ flow rate are the important factors that determine the airway pressure in the trachea during $\mathrm{O}_{2}$ insufflation. In conclusion, overlooked mechanical factors dangerously increase airway pressure during apnea testing. —— brain death; apnea testing; barotrauma; organ donation; airway simulator

(C) 2007 Tohoku University Medical Press

Brain death (BD) is defined as irreversible loss of the brain functions, including the brainstem. Unresponsiveness or coma, absence of brainstem reflexes and apnea have been accepted as diagnostic criteria for BD by American Academy of Neurology (AAN) (The Quality Standards Subcommittee of the American Academy of Neurology 1995). Apnea testing (AT) is one of the cardinal requisites that should be completed in the diagnosis of BD (Saposnik et al. 2000).

Preventing from hypoxemia while allowing the arterial partial carbondioxide pressure to rise above the threshold level, is the key point of AT. There are mainly three methods to provide sufficient $\mathrm{O}_{2}$ to patient during AT; apneic oxygenation, hypoventilation and continuous positive airway pressure (CPAP) (Lang and Heckmann 2005;

Received July 7, 2006; revision accepted for publication November 22, 2006.

Correspondence: Çimen Olguner, Dokuz Eylül University School of Medicine, Department of Anesthesiology and Reanimation, Balçova, 35340, İzmir, Turkey.

e-mail: cimen.olguner@deu.edu.tr 
Levésque et al. 2006). In the hypoventilation and CPAP methods the patient is not disconnected from mechanical ventilator but minute ventilation volue is reduced to a very low level such as 0.5 $2 \mathrm{~L} \mathrm{~min}^{-1}$ (Lang and Heckmann 2005) or ventilation mode is changed to CPAP mode with $100 \%$ $\mathrm{O}_{2}$ (Levésque et al. 2006), respectively.

Apneic oxygenation is still widely accepted method for AT and described as follows in the guideline of AAN; ventilatory assistance is discontinued and $6 \mathrm{~L} \mathrm{~min}^{-1} 100 \% \mathrm{O}_{2}$ is delivered into the trachea via an $\mathrm{O}_{2}$ catheter optionally placed "at the level of the carina" while waiting for spontaneous respiratory movements (The Quality Standards Subcommittee of the American Academy of Neurology 1995). However, even if apneic oxygenation is performed as described in the AAN guideline, hypoxemia, bradycardia, respiratory acidosis, hypotension and pneumothorax may occur (Rudolf et al. 1998; Saposnik et al. 2004). Although pneumothorax was decribed as a rare complication in the literature, authors proposed that it is more frequently encountered in clinical practice (Zisfein and Marks 1999). Diameter of the $\mathrm{O}_{2}$ catheter and $\mathrm{O}_{2}$ flow rate are the suggested factors that may lead to pneumothorax during apneic oxygenation (Bar-Joseph et al. 1998). However, there is no agreement on the diameter and position of the $\mathrm{O}_{2}$ catheter and $\mathrm{O}_{2}$ flow rate that are used for $\mathrm{O}_{2}$ delivery into the trachea during the apneic oxygenation. We designed a simple model to determine the effect of the position and diameter of $\mathrm{O}_{2}$ catheter and the $\mathrm{O}_{2}$ flow rate on the airway pressure in the simulated model of airway and lung.

\section{Materials and Methods}

A model was designed for the evaluation of airway pressure changes during apneic oxygenation. This model was consisting of a $2.3 \mathrm{~L}$ anesthesia bag that connected to a pressure transducer, and to an endotracheal tube (ETT) via an "L" connector (Fig. 1). Oxygen catheters $\left(\mathrm{O}_{2} \mathrm{C}\right)$ (Biçakçilar, Istanbul, Turkey) in different diameters were inserted into the ETT (Kendall-Gammatron, Sampran, Thailand) for $\mathrm{O}_{2}$ insufflation. Pressure of the model was measured by a transducer (Pressure Monitoring Set, Biçakçilar, Istanbul, Turkey) and a monitor (Hewlett-Packard Viridia Component Monitoring System, Hewlett-Packard GmbH, Böblingen, Germany) in three different $\mathrm{O}_{2}$ flow rates. The pressure transducer and the monitor were specially calibrated for air. ETTs with internal diameter (ID) $7 \mathrm{~mm}, 7.5 \mathrm{~mm}$, and $8 \mathrm{~mm}$ and $\mathrm{O}_{2} \mathrm{Cs}$ with external diameter $2.66 \mathrm{~mm}, 3.33 \mathrm{~mm}, 4$ $\mathrm{mm}$, and $4.66 \mathrm{~mm}(8 \mathrm{~F}, 10 \mathrm{~F}, 12 \mathrm{~F}$, and $14 \mathrm{~F}$, respectively) were used. All the $\mathrm{O}_{2} \mathrm{Cs}$ were in the same shape with a single end hole and two side holes. ETT/ $\mathrm{O}_{2} \mathrm{C}$ ratio was calculated by dividing an internal diameter of ETT with an external diameter of $\mathrm{O}_{2} \mathrm{C}$. Twelve kinds of ETT/ $\mathrm{O}_{2} \mathrm{C}$ ratio were resulted with this formulation. Other variables

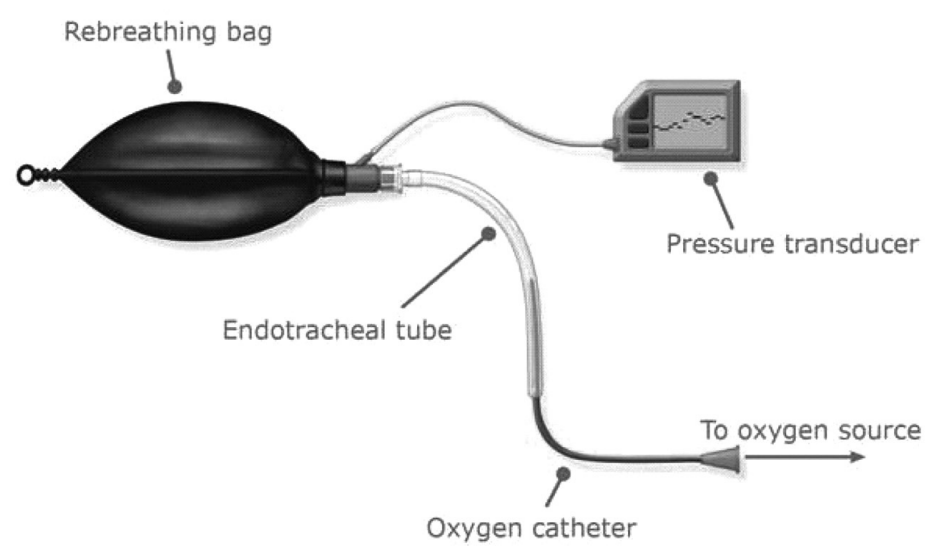

Fig. 1. The model was created with $2.3 \mathrm{~L}$ anesthesia bag that connected to a pressure transducer and to an ETT via an "L" connector. $\mathrm{O}_{2}$ catheters in different diameters were inserted into the ETT. Pressure of the system was measured by a pressure transducer and a pressure monitor under three different $\mathrm{O}_{2}$ flow rates. ETT, endotracheal tube. 
were $\mathrm{O}_{2} \mathrm{C}$ tip position in ETT and $\mathrm{O}_{2}$ flow rate. $\mathrm{O}_{2}$ catheter tip positions in ETT were as follows; 1) proximal 1/3 of the ETT, 2) mid point of the ETT, and 3) distal $1 / 3$ of the ETT (near the tip of the ETT). The $\mathrm{O}_{2}$ flow rates were 6,8 , and $10 \mathrm{~L} \mathrm{~min}^{-1}$. Nine measurements were performed for each ETT/ $\mathrm{O}_{2} \mathrm{C}$ ratio ( 3 different $\mathrm{O}_{2} \mathrm{C}$ position and 3 different $\mathrm{O}_{2}$ flow rate). When each parameter was changed (i.e., $\mathrm{O}_{2}$ flow rate or $\mathrm{O}_{2} \mathrm{C}$ position), airway pressure measurements were performed after stabilization of the model (at least $5 \mathrm{~min}$ after each parameter change). Data were presented as mean \pm standard error of mean (s.E.M.). Pearson's correlation and ANOVA were used for statistical analysis of the data. Multiple comparisons were made using Tukey's procedure. A $p$ value $<0.05$ was considered significant.

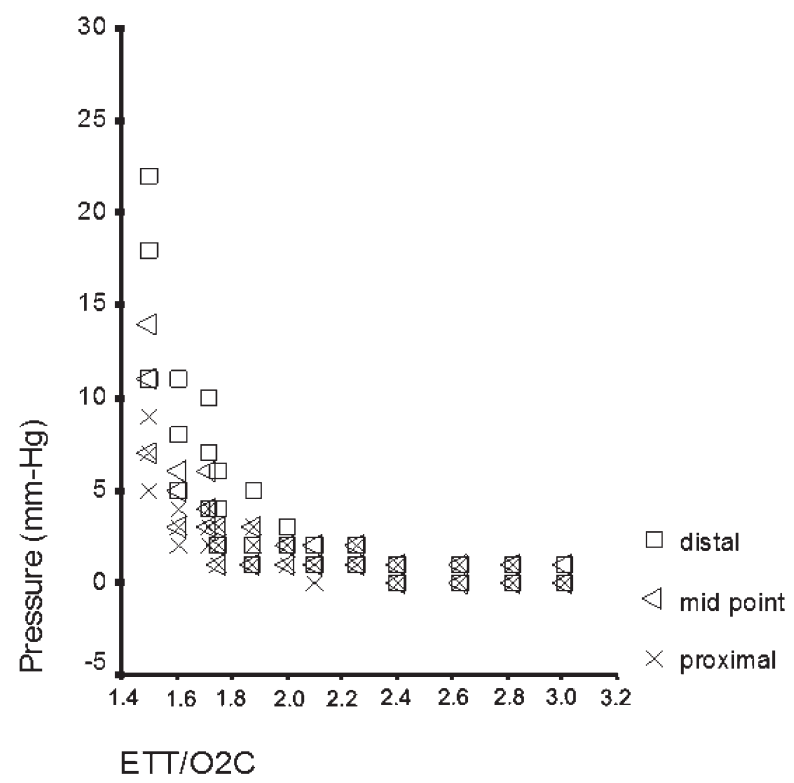

Fig. 2. Scatterplot graph of airway pressure changes according to ETT/ $\mathrm{O}_{2} \mathrm{C}$ ratio and $\mathrm{O}_{2} \mathrm{C}$ tip positions within ETT.

Airway pressure is inversely correlated with ratio of ETT $/ \mathrm{O}_{2} \mathrm{C}(p<0.01$, correlation constant $=-0.631)$ and correlated with position of $\mathrm{O}_{2} \mathrm{C}$ tip in ETT (proximal: $1 / 3$ proximal of the ETT, mid point: mid point of the ETT, distal: distal 1/3 of the ETT "near tip of the ETT") ( $p$ $=0.017$, correlation constant $=0.229)$. There is a significant increase in pressure for ETT/ $\mathrm{O}_{2} \mathrm{C}$ ratios smaller than $1.75(p<0.05)$. ETT, endotracheal tube; $\mathrm{O}_{2} \mathrm{C}$, oxygen catheter.

\section{RESULTS}

Overall 108 measurements were performed (at 12 different ETT/ $\mathrm{O}_{2} \mathrm{C}$ ratio with 3 different $\mathrm{O}_{2} \mathrm{C}$ tip positions in the ETT and different $\mathrm{O}_{2}$ flow rates). Mean airway pressure was $2.7 \pm 0.35$ $\mathrm{mmHg}$, mean $\mathrm{O}_{2}$ flow was $8 \pm 0.15 \mathrm{~L} \mathrm{~min}^{-1}$ and mean ETT/ $\mathrm{O}_{2} \mathrm{C}$ ratio was $2.1 \pm 0.04$. Increase in the airway pressure significantly correlated with $\mathrm{O}_{2}$ flow rate $(p=0.01$, correlation constant $=$ 0.248 ), $\mathrm{O}_{2} \mathrm{C}$ tip position in ETT ( $p=0.017$, correlation constant $=0.229)$ and inversely correlated with ratio of ETT/ $\mathrm{O}_{2} \mathrm{C}(p<0.01$, correlation constant $=-0.631)$ (Figs. 2 and 3 ). The airway pressure significantly increased with the decrease in ETT $/ \mathrm{O}_{2} \mathrm{C}$ ratio and with the increase in $\mathrm{O}_{2}$ flow

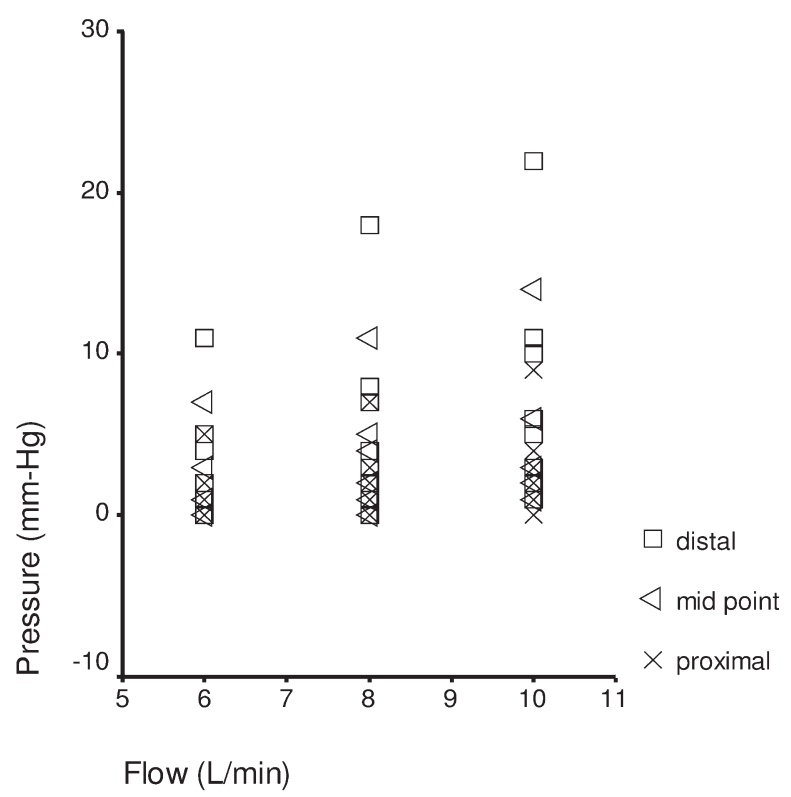

Fig. 3. Scatterplot graph of airway pressure changes according to $\mathrm{O}_{2}$ flow rate and $\mathrm{O}_{2} \mathrm{C}$ tip positions within ETT.

Airway pressure significantly increased with the change in $\mathrm{O}_{2}$ flow rate $(p=0.01$, correlation constant $=0.248)$ and position of $\mathrm{O}_{2} \mathrm{C}$ tip in ETT (proximal: $1 / 3$ proximal of the ETT, mid point: mid point of the ETT, distal: distal $1 / 3$ of the ETT "near tip of the ETT") ( $p=$ 0.017 , correlation constant $=0.229$ ). The pressure was significantly higher in $10 \mathrm{~L} \mathrm{~min}^{-1} \mathrm{O}_{2}$ flow rate compared with $6 \mathrm{~L} \mathrm{~min}^{-1} \mathrm{O}_{2}$ flow rate $(p<0.01)$.

ETT, endotracheal tube; $\mathrm{O}_{2} \mathrm{C}$, oxygen catheter. 
TABLE 1. The effect of ETT $/ \mathrm{O}_{2} \mathrm{C}$ ratio on airway pressure.

\begin{tabular}{ccc}
\hline $\mathrm{ETT} / \mathrm{O}_{2} \mathrm{C}$ & $n$ & Airway pressure $(\mathrm{mmHg})$ \\
\hline 1.50 & 9 & $11.5 \pm 1.8^{*}$ \\
1.61 & 9 & $5.2 \pm 0.9^{*}$ \\
1.72 & 9 & $4.7 \pm 0.8^{*}$ \\
1.75 & 9 & $2.6 \pm 0.5$ \\
1.88 & 9 & $2.1 \pm 0.6$ \\
2.00 & 9 & $1.8 \pm 0.7$ \\
2.10 & 9 & $1.1 \pm 0.2$ \\
2.25 & 9 & $1.4 \pm 0.2$ \\
2.40 & 9 & $0.6 \pm 0.2$ \\
2.63 & 9 & $0.5 \pm 0.5$ \\
2.82 & 9 & $0.3 \pm 0.2$ \\
3.01 & 9 & $0.2 \pm 0.2$ \\
\hline
\end{tabular}

ETT $/ \mathrm{O}_{2} \mathrm{C}$ ratio was calculated by dividing ETT internal diameter with $\mathrm{O}_{2} \mathrm{C}$ external diameter. Nine measurements for each ETT $/ \mathrm{O}_{2} \mathrm{C}$ ratio were done for three different $\mathrm{O}_{2}$ flow rates $\left(6,8\right.$, and $\left.10 \mathrm{~L} \mathrm{~min}^{-1}\right)$ while keeping the $\mathrm{O}_{2} \mathrm{C}$ tip in three different positions in the ETT (1/3 proximal of the ETT, mid point of the ETT and distal $1 / 3$ of the ETT "near tip of the ETT") (Fig. 2).

Airway pressure significantly increased with the decrease in ETT $/ \mathrm{O}_{2} \mathrm{C}$ ratio.

ETT, endotracheal tube; $\mathrm{O}_{2} \mathrm{C}$, oxygen catheter.

Data are shown as mean \pm S.E.M.

${ }^{*} p<0.05$ compared with other groups that have greater ETT/ $\mathrm{O}_{2} \mathrm{C}$ ratio than 1.75.

rate $(p<0.01)$ (Tables 1 and 2). The results were summarised according to ETT/ $\mathrm{O}_{2} \mathrm{C}$ ratio (Table 1 and Fig. 2) and $\mathrm{O}_{2}$ flow rate (Table 2 and Fig. 3) while keeping the $\mathrm{O}_{2} \mathrm{C}$ tip in 3 different positions. The pressure was not significantly influenced by the $\mathrm{O}_{2} \mathrm{C}$ tip position (Table 3 ). The airway pressure was significantly higher in $\mathrm{ETT} / \mathrm{O}_{2} \mathrm{C}$ ratio smaller than 1.75 compared with ratio greater than $1.75(p<0.05)$ (Table 1$)$. The airway pressure significantly increased in $10 \mathrm{~L} \mathrm{~min}^{-1} \mathrm{O}_{2}$ flow rate compared with $6 \mathrm{~L} \mathrm{~min}^{-1} \mathrm{O}_{2}$ flow rate $(p<0.01)$. The airway pressure was not significantly different in $8 \mathrm{~L} \mathrm{~min}^{-1} \mathrm{O}_{2}$ flow rate compared with 6 and $10 \mathrm{~L} \mathrm{~min}^{-1}$ (Table 2).
TABle 2. The effect of $\mathrm{O}_{2}$ flow on airway pressure.

\begin{tabular}{ccc}
\hline $\mathrm{O}_{2}$ Flow L $\mathrm{min}^{-1}$ & $n$ & Airway pressure $(\mathrm{mmHg})$ \\
\hline 6 & 36 & $1.6 \pm 0.2$ \\
8 & 36 & $2.6 \pm 0.3$ \\
10 & 36 & $3.8 \pm 0.4^{*}$ \\
\hline
\end{tabular}

Airway pressure was measured at each $\mathrm{O}_{2}$ flow rate for 12 different ETT/ $\mathrm{O}_{2} \mathrm{C}$ ratio (Table 1) while keeping the $\mathrm{O}_{2} \mathrm{C}$ tip in three different positions in the ETT (1/3 proximal of the ETT, mid point of the ETT and distal 1/3 of the ETT "near tip of the ETT") (Fig. 3). Airway pressure significantly increased with the increase of $\mathrm{O}_{2}$ flow rate.

ETT, endotracheal tube; $\mathrm{O}_{2} \mathrm{C}$, oxygen catheter.

Data are shown as mean \pm S.E.M.

${ }^{*} p<0.01$ compared with $6 \mathrm{~L} \mathrm{~min}^{-1} \mathrm{O}_{2}$ flow rate.

TABle 3. The effect of $\mathrm{O}_{2} \mathrm{C}$ tip position in ETT on airway pressure.

\begin{tabular}{lcc}
\hline \multicolumn{1}{c}{ Position } & $n$ & Airway pressure $(\mathrm{mmHg})$ \\
\hline Proximal 1/3 & 36 & $1.8 \pm 0.2$ \\
Mid point & 36 & $2.4 \pm 0.3$ \\
Distal 1/3 & 36 & $3.8 \pm 0.6$ \\
\hline
\end{tabular}

All measurements for each $\mathrm{O}_{2} \mathrm{C}$ tip position in the ETT (1/3 proximal of the ETT, mid point of the ETT and distal $1 / 3$ of the ETT "near tip of the ETT") were done for 12 different ETT $/ \mathrm{O}_{2} \mathrm{C}$ ratio (Table 1) and for the three different $\mathrm{O}_{2}$ flow rates $(6,8$ and $10 \mathrm{~L}$ $\min ^{-1}$ ).

The $\mathrm{O}_{2} \mathrm{C}$ tip position alone has no effect on airway pressure. catheter

ETT, endotracheal tube; $\mathrm{O}_{2} \mathrm{C}$, oxygen

Data are shown as mean \pm S.E.M.

\section{Discussion}

In this in vitro study, we demonstrated that airway pressure changes significantly correlated with the ratio of ETT/ $\mathrm{O}_{2} \mathrm{C}, \mathrm{O}_{2} \mathrm{C}$ tip position in the ETT, and $\mathrm{O}_{2}$ flow rate. Particularly, the increase in airway pressure was significant if the $\mathrm{O}_{2}$ flow 
rate was higher than $8 \mathrm{~L} \mathrm{~min}^{-1}$. The pressure changes were not significant if the $\mathrm{ETT} / \mathrm{O}_{2} \mathrm{C}$ ratio was greater than 1.75 .

The $\mathrm{O}_{2} \mathrm{C}$ that is positioned beyond the tip of the ETT carries the risk of catheterization of one of the bronchus or being in wedge position with trachea as stated previously (Bar-Joseph et al. 1998). Although the independent effect of the $\mathrm{O}_{2} \mathrm{C}$ tip position on airway pressure was not statistically significant, the correlation between the airway pressure and $\mathrm{O}_{2} \mathrm{C}$ tip position in ETT was significant. Therefore the $\mathrm{O}_{2} \mathrm{C}$ tip position in the ETT may contribute to airway pressure increase when combined with the effects of $\mathrm{O}_{2}$ flow rate and ETT $/ \mathrm{O}_{2} \mathrm{C}$ ratio.

Apnea testing related pneumothorax was first reported by Bar-Joseph et al. In order to avoid pneumothorax, the authors proposed that the $\mathrm{O}_{2} \mathrm{C}$ diameter should be significantly narrower than the diameter of the ETT, the tip of the $\mathrm{O}_{2} \mathrm{C}$ should not exceed the tip of the ETT to avoid wedge position with trachea and $\mathrm{O}_{2}$ flow rate should not exceed 6 $\mathrm{L} \mathrm{min}^{-1}$ (Bar-Joseph et al. 1998). Saposnik et al. (2000) reported a case with pneumothorax and pneumoperitoneum that occurred during AT. They questioned the safety of AT and identified risk factors that were the $\mathrm{O}_{2} \mathrm{C}$ position in the ETT and the diameter disproportion between the ETT and the $\mathrm{O}_{2} \mathrm{C}$. Additional three cases of pneumothorax have been reported by Vivien et al. (2001). They proposed that a $12 \mathrm{~F}$ catheter should be advanced only $5 \mathrm{~cm}$ into the ETT and the $\mathrm{O}_{2}$ flow rate should not exceed $8 \mathrm{~L} \mathrm{~min}^{-1}$ to avoid this complication. After application of these rules they have not seen any such complication (Vivien et al. 2001).

All data obtained from the above cases indicate that mainly three factors may play a role in the occurrence of pneumothorax during AT. These factors are; 1) the ratio of $\mathrm{ETT} / \mathrm{O}_{2} \mathrm{C}, 2$ ) the $\mathrm{O}_{2} \mathrm{C}$ tip position in the ETT and 3) $\mathrm{O}_{2}$ flow rate. In general $\mathrm{O}_{2}$ flow rate of $6 \mathrm{~L} \mathrm{~min}^{-1}$ has been suggested during AT. However, different flow rates ranging from 6 to $15 \mathrm{~L} \mathrm{~min}^{-1}$ have been reported in the literature (Bar-Joseph et al. 1998; Saposnik et al. 2000; Vivien et al. 2001). Proper positions of the $\mathrm{O}_{2} \mathrm{C}$ tip in trachea are not clearly described in previous studies. The position is defined as "at the level of the carina" in the AAN guideline and "not in wedge position with trachea" by others (The Quality Standards Subcommittee of the American Academy of Neurology 1995; Wijdicks 1995; Bar-Joseph et al. 1998). The relation between the external diameter of $\mathrm{O}_{2} \mathrm{C}$ and internal diameter of ETT is also obscure in the literature. The suggestion by authors that the use of $12 \mathrm{~F}$ $\mathrm{O}_{2} \mathrm{C}$ in all patients for $\mathrm{O}_{2}$ insufflation seems not applicable because internal diameters of ETT differ from patient to patient (Vivien et al. 2001). Moreover, AAN guideline includes any proposal about the proper $\mathrm{O}_{2} \mathrm{C}$ diameter (The Quality Standards Subcommittee of the American Academy of Neurology 1995).

In considering the mechanical factors in AT, the shape of the $\mathrm{O}_{2} \mathrm{C}$ is also noteworthy. Dyer et al. (2003) tested tracheal gas insufflation catheter in different shapes in a model that simulated airways. The pressure changes were minimal with the single side hole catheter and multiple side holes catheter. We standardized our study by using $\mathrm{O}_{2} \mathrm{C}$ in one shape in different diameters in all measurements.

Because there may be other contributing factors to cause pneumothorax during in vivo conditions (i.e., pulmonary infections, acute respiratory distress syndrome and secretions), it is difficult to find a clinical threshold pressure that may cause pneumothorax. Entrapping air by secretions in the small and intermediate airways may cause localized pulmonary high-pressure zones and alveolar burst without causing high pressure within the main airways.

Organ donation contributes to survival of the patients waiting for organ transplantation. The complications such as pneumothorax occurring during AT for diagnosis of the BD may lead to donor loss (Sharples et al. 1997; Bar-Joseph et al. 1998; Goudreau et al. 2000). Thus, methods in performing AT would be revised concerning the possible complications and especially the position of the $\mathrm{O}_{2} \mathrm{C}$, the $\mathrm{O}_{2}$ flow rate and the ratio of ETT/ $\mathrm{O}_{2} \mathrm{C}$.

We are aware that our simple model is not capable enough for simulating human airways and 
lungs. We concluded that the data from the present study may give an idea to clinicians about the possible dramatic airway pressure rises during AT which are easily affected from minor mechanical changes.

\section{References}

Bar-Joseph, G., Bar-Lavie, Y. \& Zonis, Z. (1998) Tension pneumothorax during apnea testing for the determination of brain death. Anesthesiology, 89, 1250-1251.

Dyer, I.R., Esmail, M., Findlay, G., Mecklenburgh, J.S. \& Dingley, J. (2003) Effect of catheter design on tracheal pressures during tracheal gas insufflation. Eur. J. Anaesthesiol., 20, 740-744.

Goudreau, J.L., Wijdicks, E.F. \& Emery, S.F. (2000) Complications during apnea testing in the determination of brain death: predisposing factors. Neurology, 55, 1045-1048.

Lang, C.J. \& Heckmann, J.G. (2005) Apnea testing for the diagnosis of brain death. Acta Neurol. Scand., 112, 358-369.

Levésque, S., Lessard, M.R., Nicole, P.C., Langevin, S., LeBlanc, F., Lauzier, F. \& Brochu, J.G. (2006) Efficacy of a T-piece system and a continuous positive airway pressure system for apnea testing in the diagnosis of brain death. Crit. Care. Med., 34, 2213-2216.

Rudolf, J., Haupt, W.F., Neveling, M. \& Grond, M. (1998) Potential pitfalls in apnea testing. Acta Neurochir. (Wien), 140, 659-663.

Saposnik, G., Rizzo, G. \& Deluca, J.L. (2000) Pneumothorax and pneumoperitoneum during the apnea test: how safe is this procedure? Arq. Neuropsiquiatr., 58, 905-908.

Saposnik, G., Rizzo, G., Vega, A., Sabbatiello, R. \& Deluca, J.L. (2004) Problems associated with the apnea test in the diagnosis of brain death. Neurol. India, 52, 342-345.

Sharples, A., Dearlove, O.R., Yates, R. \& Stewart, D. (1997) Apnoea testing in children. Anaesthesia, 52, 503.

The Quality Standards Subcommittee of the American Academy of Neurology (1995) Practice parameters for determining brain death in adults (summary statement). Neurology, $\mathbf{4 5}$, 1012-1014.

Vivien, B., Haralambo, M.S. \& Riou, B. (2001) Barotrauma during apnea testing for the determination of brain death. Ann. Fr. Anesth. Reanim., 20, 370-373.

Wijdicks, E.F. (1995) Determining brain death in adults. Neurology, 45, 1003-1011.

Zisfein, J. \& Marks, S.J. (1999) Tension pneumothorax and apnea tests. Anesthesiology, 91, 326. 